
January 1935

\title{
USE OF THE PIPETTE METHOD IN THE FINENESS TEST OF MOLDING SAND
}

\author{
By Clarence E. Jackson and C. M. Saeger, Jr.
}

\section{ABSTRACT}

The fineness, or the size distribution, of the constituent particles of a material is an important factor in determining many of the physical characteristics. No great difficulty is encountered in sizing the larger particles by the use of sieves, but for particles finer than 50 microns in diameter other methods must be employed. The pipette method has been satisfactorily used in analysis of particle sizes of soils. Details of the development and use of the pipette method in the fineness test of molding sands are outlined in this paper. The method of computation and scope of results are shown by typical examples. A rapid method suitable for foundry control work and routine testing is suggested.

\section{CONTENTS}

I. Introduction $\ldots \ldots$

II. The pipette method... 60

III. Details of procedure 63

IV. Results obtained by the pipette method

V. Summary

\section{INTRODUCTION}

The determination of fineness is one of the most important tests made on a molding sand. The permeability, strength, refractoriness, and moisture required for tempering the sand, as well as the surface finish obtained on castings made in the sand, to a large degree depend upon the size distribution of the constituent particles. In the present method for classification adopted as a standard by the American Foundrymen's Association ${ }^{1}$ the particles of a molding sand are classed in two groups by means of a sedimentation method, the larger particles being termed "grain material", and the smaller particles, "clay substance." A sample of molding sand is dispersed in distilled water and allowed to settle. Clay substance is the portion which settles at a rate less than $1 \mathrm{in} . / \mathrm{min}$. The faster settling material constitutes the grain and is further classified by a series of sieves, the finest being a no. 270 sieve. The portion of the grain which passes through a no.

\footnotetext{
1 Testing and Grading Foundry Sands, Standards and Tentative Standards. Fineness Test. p. 86. American Foundrymen's Association, Chicago.
} 
270 sieve and still settles at a rate faster than $1 \mathrm{in} . / \mathrm{min}$. in distilled water, is called "pan material" or "silt".

In view of recent developments in the methods 234567 for measurement of subsieve particle sizes, it was felt that improvement in the method for sizing the particles of molding sands was desirable. After a preliminary study of the available methods, the pipette method was selected as being the most suitable for this particular use.

\section{THE PIPETTE METHOD}

The pipette method was developed independently by Robinson in Wales ${ }^{8}$, Krauss in Germany ${ }^{9}$, and Jennings, Thomas, and Gardner ${ }^{10}$ in the United States. It is used in soil analysis by the Bureau of Chemistry and Soils of the U. S. Department of Agriculture and is readily adaptable to the analysis of molding sands. An advantage of this method is that determinations of many size classes can be easily performed on one sample.

The pipette method of determining size classes depends on the relation of the size of a particle to its velocity when allowed to settle freely in a suitable medium. The relation between size and rate of fall of solid spherical particles in any liquid is given by the following form of Stokes' equation ${ }^{11}$ :

$$
t=\left\{\frac{18 H u}{\left(P_{1}-P_{2}\right) g d^{2}}\right\} 10^{8}
$$

Where $t=$ time of settling in seconds.

$H=$ depth of settling in centimeters.

$u=$ viscosity of dispersing medium in poises.

$P_{1}=$ density of particles in $\mathrm{g} / \mathrm{cm}^{3}$.

$P_{2}=$ density of dispersing medium in $\mathrm{g} / \mathrm{cm}^{3}$.

$g=$ acceleration of gravity, $980 \mathrm{~cm} / \mathrm{sec} / \mathrm{sec}$.

$d=$ diameter of particles in microns $(1 \mu=0.001 \mathrm{~mm})$.

This equation although subject to certain limitations ${ }^{12}$ has been used in the grading by sedimentation methods of molding sand or other particles of irregular shape. This application involves the assumption that the effective diameter of an irregular particle is the same as the diameter of a solid spherical particle which settles at the same rate. A classification of irregular particles, according to Stokes'

2 H. G. Schurecht, Elutriation tests on American kaolins, J. Am. Ceram. Soc. 3, 355 (1920).

$3 \mathrm{H}$ G. Schurecht, Sedimentation as a means of classifying extremely fine particles. J. Am. Ceram. Soc. 4, $812(1921)$.

4 L. Wagner, A rapid method for the determination of the specific surface of Portland cement. Proc. Am. Soc. Testing Mats. 33, part II, 553 (1933).

5 R. C. Thoreen, Comments on the hydrometer method of mechanical analysis. Public Roads 14, 93 (1933)

${ }^{6} \mathrm{~L}$. B. Olmstead, L. T. Alexander, and H. E. Middleton. A pipette method of mechanical analysis of soils based on improved dispersion procedure. U. S. Department of Agriculture, Washington, Tech. Bul. 170 $(1930)$.

W. C. A. Krumbein, History of the principles and methods of mechanical analysis, J. Sedimentary Petrology 2,89 (1932).

8 J. Agr. Sci. 12, 306 (1922).

9 Intern. Mitt. z. Bodenkunde 13, 147 (1923).

10 Soil. Sci. 14, 485 (1922).

11 Cambridge Phil. Soc. Trans. 9, 8 (1851-56).

12 B. A. Keen, The Physical Properties of the Soil, chapter II, Mechanical Analysis, p. 37. Longmans. Green \& Co. (1931). 
equation is therefore on the basis of effective diameter rather than actual dimensions.

The principle of the pipette method is as follows: If solid particles suspended in a liquid are allowed to settle freely, then, in accordance with Stokes' equation, after a selected time interval, $t$, all the particles larger than diameter, $d$, will have fallen below a level designated as $\mathrm{M}$ (fig. 1). A layer at $M$ will be free from large particles, whose velocity of fall exceeds $H / t$, but will contain all particles having less velocity in the same concentration as in the original suspension. ${ }^{13}$ By means of a pipette whose tip is immersed to level M, a sample of the suspension may be obtained which will contain only particles smaller than diameter $d$. A choice of time and level to effect a separation at any desired diameter, can be made from Stokes' equation.

It is thus possible to separate the suspended material into 2 grades, coarse and fine, by means of a single pipette sample or to separate further and classify the material by means of additional pipette samples taken at selected intervals of time. In this investigation an effective diameter of $20 \mu$ was adopted as the dividing size between coarse material (grain) and fine material (clay substance) of molding sand. This distinction between grain material and clay substance is in agreement with the American Foundrymen's Association procedure. ${ }^{14}$

A nomograph, based on Stokes' equation, shown in figure 2, furnishes a convenient means for determining the interrelation of temperature, particle diameter of molding sand, and time of settling to an arbitrary selected depth of 5 inches in distilled water. Data on viscosity of distilled water were taken from the work of Jackson and Bingham $;{ }^{15}$ the density of molding sand (2.65) was taken from the work of Searle ${ }^{16}$ on

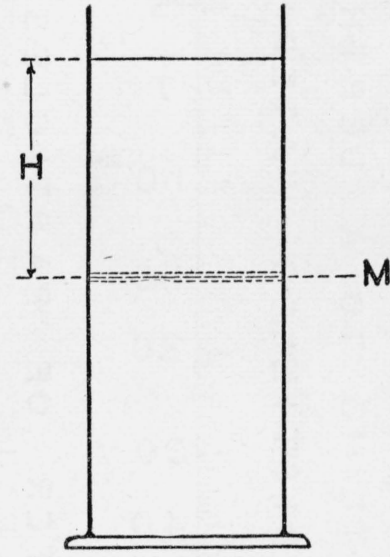

Figure 1.-Diagram for $e x-$ planation of principle of pipette method. siliceous materials. A straight line across the 3 branches of the nomograph indicates the interrelation of temperature, particle diameter, and time of settling; for example, the broken line in figure 2 shows that after 5 minutes' settling at $27^{\circ} \mathrm{C}$ the suspension 5 inches below the surface will be free from all particles larger than $20 \mu$ in effective diameter.

\footnotetext{
${ }^{13}$ For an analysis of the fall of particles from a suspension see M. Kohn, Particle size determination by means of pipette analysis Tonindustrie Zeitung 531, 730 (1927).

${ }_{14}$ Testing and Grading Foundry Sands, Standards and Tentative Standards. Fineness Test, p. 86. American Foundryman's Association, Chicago.

${ }_{15}$ Bul. BS 14, 59 (1918) S298.

16 Chemistry and Physics of Clays, p. 218. Ernest Benn, Limited, London (1924).
} 


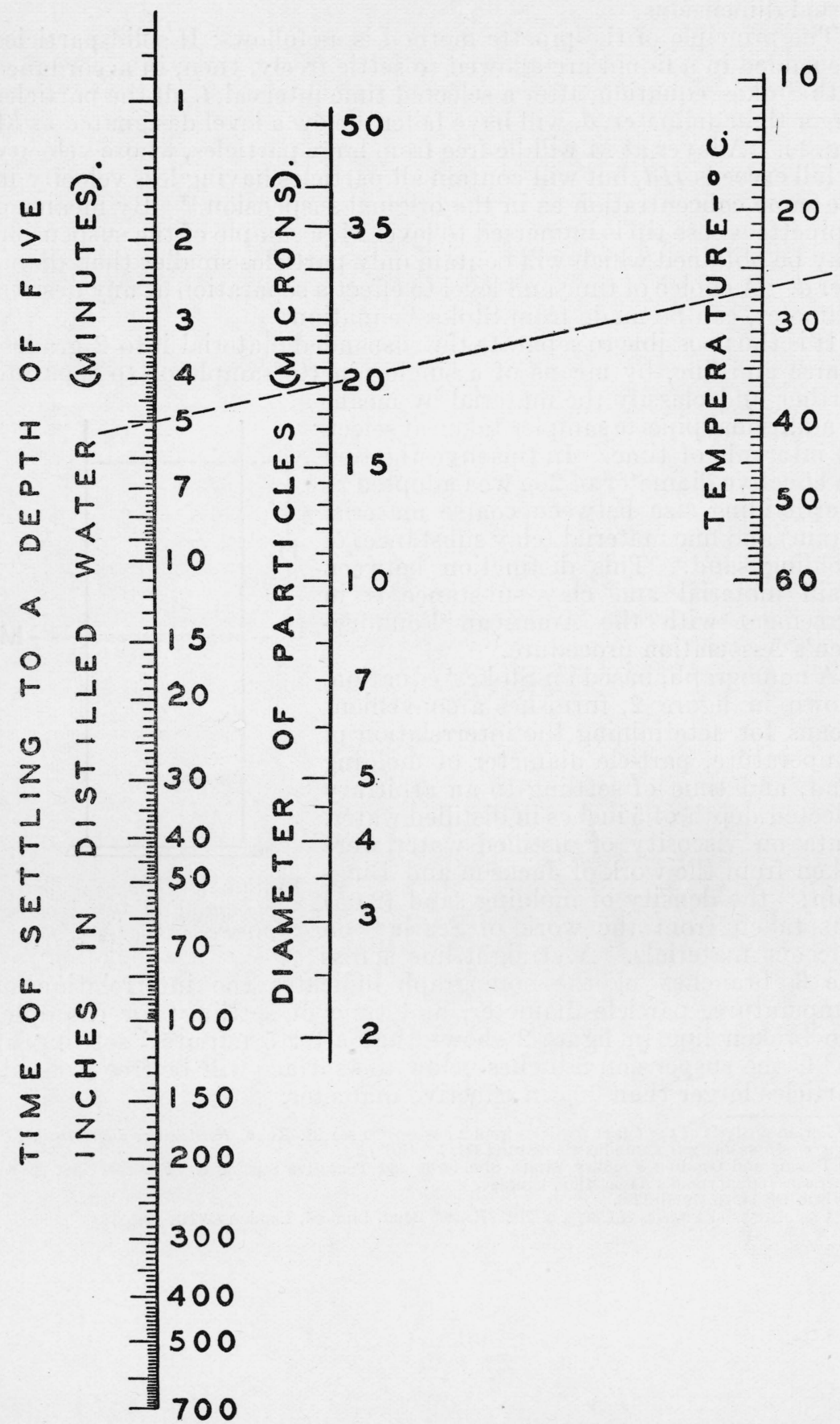

FIGURE 2.-Relation of temperature, time of settling, and particle size of molding sand. 


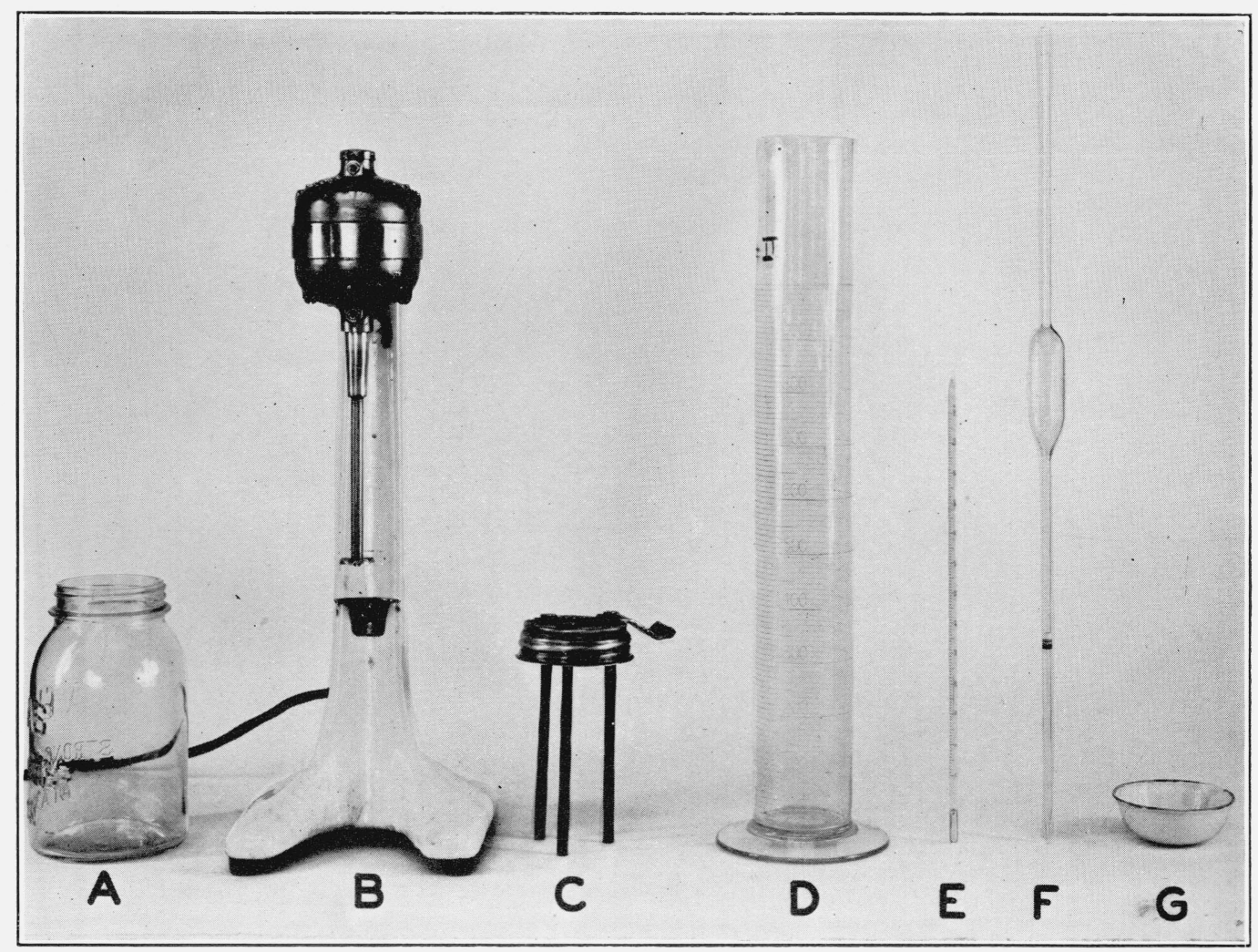

FIGURE 3.-Apparatus used in the pipette method of testing the fineness of molding sand.

A, Quart fruit jar; B, milk-shake stirrer; C, baffle system; D, 1,000-ml graduated cylinder; E, thermometer; F, transfer pipette; G, evaporating dish, 3-in. diameter. 


\section{DETAILS OF PROCEDURE}

A suspension of the molding sand for the pipette method is prepared as follows: A 50-g sample is placed in a glass jar (1-quart capacity) with a screw top, covered with $475 \mathrm{ml}$ of distilled water, and $25 \mathrm{ml}$ of a 1 percent aqueous solution of sodium hydroxide is added to deflocculate the clay. The sand is dispersed for a period of 5 minutes in the $500 \mathrm{ml}$ of solution by means of a small electrically operated stirrer. Baffles, consisting of 3 pieces of brass rod ( $3 / 16$-inch diameter) projecting perpendicularly from a brass ring held in place at the top of the jar by the jar cap, hasten the process of dispersion. Snugly fitting rubber tubing on the baffle rods prevents excessive break-up of the grain material. The arrangement of these baffle rods is shown in figure 3, together with other equipment used in the dispersion of the sample, and in the sampling and analysis by the pipette method. The dispersed suspension together with the rinsings of the jar are transferred to a graduated cylinder of 1-liter capacity and distilled water is added to bring the volume up to 1 liter. After closing the open end of the cylinder, it is inverted and agitated for a period of 1 minute to insure uniform mixing of the original dispersion and the added water. The graduated cylinder is then set upright; a stop watch is started, signifying the beginning of actual settling. The temperature of the suspension, observed by means of a thermometer determines, from the nomograph (fig. 2), the time of settling of the suspension.

About 10 seconds before the indicated time has elapsed a $25-\mathrm{m}$ ] pipette, the volume of which has been accurately determined, is inserted into the suspension until the tip is 5 inches below the surface. When the time limit is reached, the pipette is filled rapidly (in less than 30 seconds). The contents are transferred to a weighed porcelain evaporating dish; the pipette is rinsed with distilled water and the rinsings added to the sample in the evaporating dish. After evaporating to dryness at a temperature of 105 to $110^{\circ} \mathrm{C}$, preferably in an oven, the dish is allowed to cool in a desiccator and is then reweighed. ${ }^{17}$ A balance accurate to $1 \mathrm{mg}$ should be used. The pipette is thorougly cleaned and dried after each sampling by rinsing with alcohol and ether. Sampling may be repeated at progressive intervals to obtain additional size separations. Duplicate determinations may be obtained after reagitation of the remaining suspension. For routine work, duplicate pipette samples are taken representing a separation at $20 \mu$.

The weight of the dried sample in the evaporating dish must be corrected for the small amount of sodium hydroxide which is present. Twenty-five $\mathrm{ml}$ of a 1-percent solution of sodium hydroxide, equivalent to $0.25 \mathrm{~g}$ of sodium hydroxide, was present in the $500 \mathrm{ml}$ of solution which was diluted to 1,000 $\mathrm{ml}$. Each $25-\mathrm{ml}$ sample of the diluted solution therefore contains $0.025 \times 0.25=0.006 \mathrm{~g}$ of sodium hydroxide. This weight must be subtracted from the weight of the dried material which was obtained from a pipette sample of the suspension.

17 For foundry control work and routine testing for clay substance a complete determination may be made in approximately 30 minutes by carefully evaporating the pipette portion in a weighed $250 \mathrm{ml}$ heatresisting glass beaker over a low gas flame, cooling and reweighing. This weight affords a basis for the clay substance calculation. 
To obtain the size distribution of the grain material of the sample the remaining suspension is emptied on a wet no. 270 sieve and washed by a gentle stream of water which carries most of the fine particles through the sieve. The sieve containing the coarser grain is dried for $1 / 2$ hour in an oven at a temperature of 105 to $110^{\circ} \mathrm{C}$. After cooling, the dried grain material is weighed and is classified by means of sieves according to the regular American Foundrymen's Association practice. ${ }^{18}$ This indicates the size distribution of the coarser material, from the particles of largest diameter down to the smallest particles retained on a no. 270 sieve. Since the no. 270 sieve has a nominal opening of $0.053 \mathrm{~mm}$, particles having a diameter of approximately $50 \mu$ or less will pass through this sieve. ${ }^{19}$ Analysis of the pipette sample, as already described, determines the amount of clay substance finer than $20 \mu$. The material between 50 and $20 \mu$ in size, called "pan material" or "silt", is determined as the difference between the original weight of the sample and the combined weights of the material greater than $50 \mu$ and less than $20 \mu$.

\section{RESULTS OBTAINED BY THE PIPETTE METHOD}

The following data and computations illustrate the information obtained from a fineness analysis of a 50 -g sample of fine brass molding sand.

Determination of clay substance (material less than $20 \mu$ in diameter):

Temperature__._._.

Time of settling

Volume of pipette... 11

Dry weight of clay substance and sodium hydroxide in pipette portion $g_{--} \quad 150$

Weight of sodium hydroxide in pipette portion

Net weight of clay substance in pipette sample

Total weight of clay substance in $1000 \mathrm{ml}$ of original suspension $(0.144 \times$

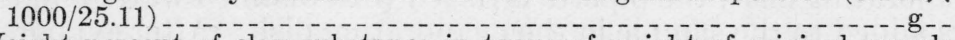

Weight percent of clay substance in terms of weight of original sample $(5.73 \times 100 / 50) \ldots \ldots$

Determination of grain material (material retained on no. 270 sieve): Total weight of dry grain retained on no. 270 sieve, $26.72 \mathrm{~g}$ (53.4 percent).

This weight of dry grain is further classified by use of a series of sieves as shown in the summary of results.

Determination of pan material or silt (material passing a no. 270 sieve and larger than $20 \mu$ ):

Weight of original sample

Grams.

Combined weight of clay substance $(5.73 \mathrm{~g})$ and weight of grain coarser

than no. 270 sieve $(26.72 \mathrm{~g}) \ldots$

Weight of silt, by difference

\footnotetext{
18 Testing and Grading Foundry Sands, Standards and Tentative Standards. Fineness Test, p. 86. American Foundryman's Association, Chicago.

${ }_{10}$ In ordinary mechanical analyses of sand no attention is paid to absolute sizes of grains but the nominal sizes of the screen openings are taken as the sizes of separation. For further discussion the reader is referred to Techn. Pap. BS 48, 50 (1915) T48.
} 
Summary of the results obtained for a sample of fine brass molding sand:

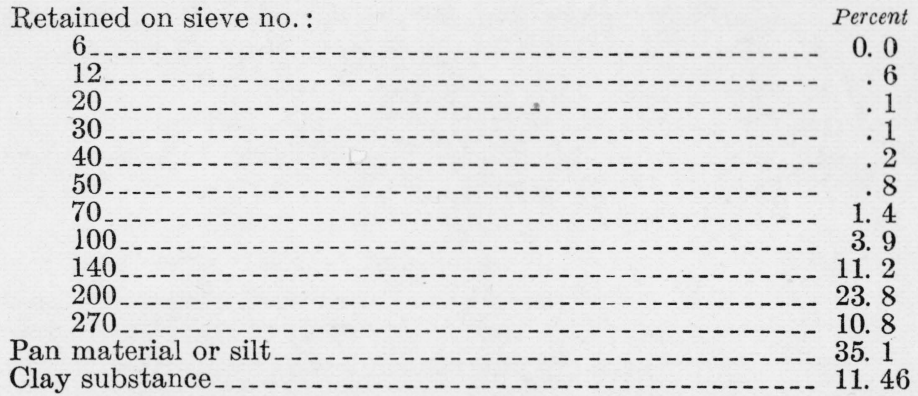

Such a summary constitutes the conventional report of the fineness of a molding sand.

When further information is desired as to the size distribution of the fine portion of a sand, relative data suitable for comparison can be obtained by use of the pipette method. For example, the material finer than that retained on a no. 270 sieve in the above sample of fine brass molding sand showed the followin ${ }^{*}$ size distribution:

$\begin{aligned} \text { Percent } & \end{aligned}$

Material passing a no. 270 sieve_... 646

Material with an effective diameter less than $\left\{\begin{array}{lr}35 \mu & 16.2 \\ 20 \mu & 9.5 \\ 10 \mu & 7.0\end{array}\right.$

In order to establish the reproducibility of results obtained by the pipette method, 5 successive pipette samples for a $20 \mu$ separation were taken under similar conditions from a suspension of a sample of molding sand. The weights of the dry material less than $20 \mu$ in diameter, obtained from these 5 portions were $0.207,0.209,0.209$, 0.207 and $0.206 \mathrm{~g}$, which correspond to $16.5,16.6,16.6,16.5$, and 16.4 percent by weight, respectively.

\section{SUMMARY}

The pipette method is a modified sedimentation method for classifying finely divided material according to particle size. It is readily adaptable to the determination of the fineness of molding sand and has been satisfactorily used for this purpose at the National Bureau of Standards. The equipment required is easily assembled, the operation is simple, the time required for a determination is short, the information obtained is wider in scope, and the reproducibility of results is greater than is obtained by other methods now in use.

Washington, D. C., September 18, 1934. 